\title{
Pharyngeal pressure in preterm infants receiving nasal continuous positive airway pressure
}

\author{
A G De Paoli, R Lau, P G Davis, C J Morley
}

Arch Dis Child Fetal Neonatal Ed 2005;90:F79-F81. doi: 10.1136/adc.2004.052274

Pharyngeal pressures in 11 preterm infants, receiving binasal Hudson prong continuous positive airway pressure (CPAP) pressurised by bubbling bottles, were measured. The mean (95\% confidence interval) pressure drop from the prongs to the pharynx was 3.2 (2.6 to 3.7 ) $\mathrm{cm} \mathrm{H}_{2} \mathrm{O}$ with mouths open and 2.2 (1.6 to 2.8 ) $\mathrm{cm} \mathrm{H} \mathrm{H}_{2} \mathrm{O}$ with mouths closed. Mouth closure augments CPAP transmission.

C ontinuous positive airway pressure (CPAP) is an effective treatment for preterm infants with respiratory distress syndrome or apnoea or after extubation. ${ }^{1}$ Our previous research showed that short binasal prongs deliver the pressure most effectively because of low resistance. ${ }^{2}$ Whichever nasal device or pressure generating system is used, it is the pressure transmitted to the airway that is important.

The optimum CPAP for infants with various degrees of lung disease remains uncertain. It is also unknown if small differences in CPAP transmission to the airway are clinically important. The pressure in the upper airway is an important measure of how much pressure is transmitted from the CPAP system. Chilton and Brooks ${ }^{3}$ measured pharyngeal pressures in infants treated with nasal CPAP via Argyle prongs (Sherwood Medical, St Louis, Missouri, USA). The tips of non-perfused, air filled catheters were placed in the pharynx, and the end expiratory pressure measured over just five breaths. They found that, when the mouth was open, pharyngeal pressure was about $48 \pm 4 \%$ below that in the prong. However, this was not a consistent finding, as in some infants the pharyngeal pressure at end expiration was observed to fall with imposed mouth closure.

It has been suggested that ensuring that a baby's mouth is kept closed during nasal CPAP increases its effectiveness. ${ }^{4}$ The aim of this project was to characterise the pharyngeal pressure in preterm infants treated with CPAP via Hudson prongs (Hudson-RCI, Temecula, California, USA) pressurised by an underwater bottle system, and to accurately assess the effect of mouth closure.

\section{METHODS}

\section{Measurement of pharyngeal pressure}

A 6 French gauge, multi-lumen, soft, silastic catheter (Dentsleeve Pty Ltd, Adelaide, Australia) was designed so that the openings of two air perfused lumens could be positioned in the pharynx. ${ }^{5}$ The lumens for measuring pressure were $0.35 \mathrm{~mm}$ in diameter and their openings $1 \mathrm{~cm}$ apart. They were air perfused at $2 \mathrm{ml} / \mathrm{min}$ to keep the holes clear. The catheter was inserted through the mouth (seven infants) or nose (four infants). Positioning of the openings in the pharynx was aided by observing a high pressure when the distal opening entered the upper oesophageal sphincter and then the catheter was withdrawn slightly. Although nasal catheter placement permitted more stable recordings, it may have influenced nasal resistance and air leak. The catheter length enabled gastric feeds through a larger central lumen (diameter $0.75 \mathrm{~mm}$ ).

Pressure transducers (Sensym; Sensortechnics, Puchheim, Germany) measured pressure (range $0-13 \mathrm{~cm} \mathrm{H}_{2} \mathrm{O}$ ) at the external ends of the two channels. The output was amplified (Applied Measurement, Melbourne, Australia), digitised, and recorded using Spectra Physiological Software (Grove Medical Ltd, Hampton, UK, version 3.004) at $200 \mathrm{~Hz}$ and observed in real time. Before each study, the system was calibrated to a water manometer and the output offset to zero after air perfusion.

\section{Pressure response characteristics}

The system's pressure response characteristics were assessed by comparing its output with that recorded by a transducer connected directly to a pressure test chamber. As expected, there was amplitude attenuation. Damping was 15\% when a test pressure of $10 \mathrm{~cm} \mathrm{H}_{2} \mathrm{O}$ was applied at $1 \mathrm{~Hz}$ and increased considerably with increasing frequency. Importantly, the measure of interest, the mean pressure, did not vary from that recorded by the reference transducer by more than $\pm 0.1 \mathrm{~cm} \mathrm{H} \mathrm{H}_{2} \mathrm{O}$, irrespective of the frequency.

\section{The CPAP system}

Hudson prongs pressurised with the Fisher and Paykel (Auckland, New Zealand) underwater bubble CPAP device were used in this study, as this is the preferred system used at the Royal Women's Hospital, Melbourne.

\section{Mouth position}

Pharyngeal pressures were measured with the infant's mouth in both the passive and actively closed positions with pressures from the CPAP device of $3-8 \mathrm{~cm} \mathrm{H}_{2} \mathrm{O}$. Set pressures were altered by $1 \mathrm{~cm} \mathrm{H}_{2} \mathrm{O}$ increments to ensure clinical stability. The position designated as passive involved no direct measures to close the mouth during the measurement. Active mouth closure was achieved with gentle pressure applied under the infant's chin with a single finger.

Pressure in the Hudson prong was measured concurrently with a Sensym pressure transducer. Mean pharyngeal pressure measurements were taken from the longest segment of stable recording for a minimum of 20 seconds and when the system was bubbling.

A paired samples $t$ test with $95 \%$ confidence limits was used to compare differences.

Abbreviations: $95 \% \mathrm{Cl}, 95 \%$ confidence interval; CPAP, continuous positive airway pressure; $\mathrm{FIO}_{2}$, fractional inspired oxygen; $\mathrm{FG}$, French gauge; IQR, interquartile range; NICU, neonatal intensive care unit; RDS, respiratory distress syndrome 


\section{Study population}

This was an observational study on a convenience sample of stable preterm infants receiving nasal CPAP in the neonatal intensive care unit of the Royal Women's Hospital, Melbourne, Australia in 2001. The study was approved by the Royal Women's Hospital research and ethics committee, and informed parental consent was obtained.

\section{RESULTS}

The parents of 47 infants were approached for consent; 28 declined. Results from the first eight infants studied were excluded because of unacceptable error in the original amplifier (Synectics Medical, Stockholm, Sweden). The replacement amplifier was highly accurate. Results are presented for the remaining 11 infants where the replacement amplifier was used. Their median age was 14 days (interquartile range 12 to 46 ) with a mean (SD) corrected gestational age of 30.6 (1.9) weeks and a mean (SD) weight of 1151 (269) $\mathrm{g}$.

Figure 1 shows a recording from an infant exhibiting pressure change with mouth closure. It shows two channels of pharyngeal pressure and the pressure from the Hudson prong. The pressure in both channels recording pharyngeal pressure was virtually identical.

The pharyngeal pressures with the mouth in the actively closed and passive positions at different set pressures are presented as a box plot (fig 2). The increase in pharyngeal pressure with mouth closure, and a trend for the difference in pharyngeal pressure between closed and passive postures to increase with increasing set pressures from the CPAP device is apparent. The mean pharyngeal pressure always increased for each $1 \mathrm{~cm} \mathrm{H}_{2} \mathrm{O}$ increment in CPAP when the mouth was closed or passive. Not all of these incremental differences were significant. However, the number of paired values available for incremental pressure comparisons was small.

The overall mean drop in pressure from the Hudson prong to the pharynx, with the mouth in either a passive or closed position, was $2.6 \mathrm{~cm} \mathrm{H}_{2} \mathrm{O}$ (95\% CI 2.2 to 2.9) ( $\left.\mathrm{p}<0.05\right)$. The mean drop in pressure from the Hudson prong to the pharynx with the mouth in the passive position was $3.2 \mathrm{~cm} \mathrm{H}_{2} \mathrm{O}(95 \%$ CI 2.6 to 3.7) $(p<0.05)$. When the mouth was actively closed, the mean drop in pressure from the Hudson prong to the pharynx was $2.2 \mathrm{~cm} \mathrm{H}_{2} \mathrm{O}$ (95\% CI 1.6 to $\left.2.8, \mathrm{p}<0.05\right)$. The mean difference between pharyngeal pressure in the passive and closed postures was $1.1 \mathrm{~cm} \mathrm{H}_{2} \mathrm{O}$ (95\% CI 0.7 to 1.4 ) $(p<0.05)$. When the results for CPAPs of $3-4 \mathrm{~cm} \mathrm{H}_{2} \mathrm{O}$ are excluded, because they are not often used in our unit, the mean difference between pharyngeal pressure in the passive

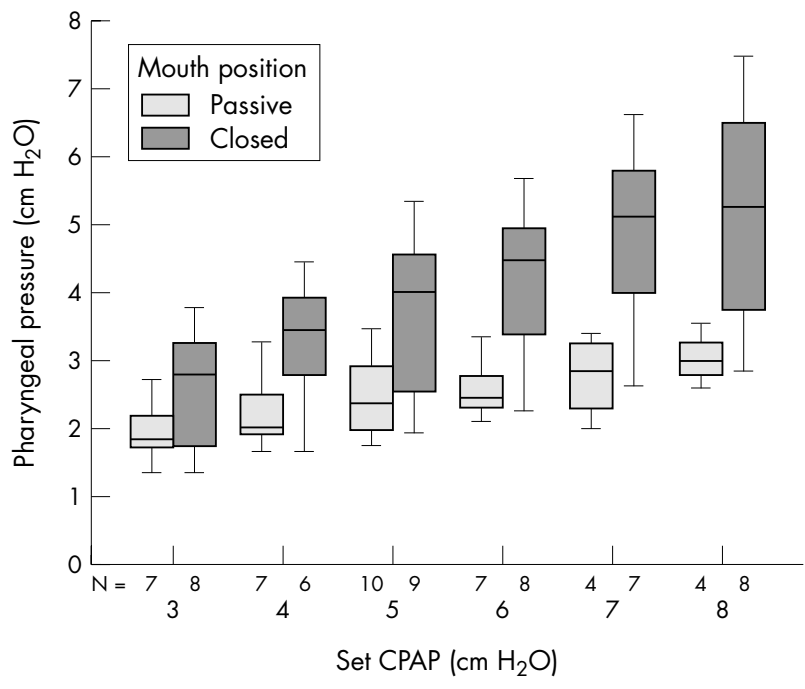

Figure 2 Set pressure versus pharyngeal pressure in passive and closed mouth positions. This shows the effect on pharyngeal pressure at continuous positive airway pressures (CPAPs) of $3-8 \mathrm{~cm} \mathrm{H} \mathrm{H}_{2} \mathrm{O}$ with the mouth open or closed. The boxes represent the interquartile range with the horizontal line at the median value. The whiskers show the $95 \%$ confidence intervals. $\mathrm{N}=$ number of observations.

and closed postures is only slightly higher at $1.2 \mathrm{~cm} \mathrm{H}_{2} \mathrm{O}$ (95\% CI 0.8 to 1.7$)(\mathrm{p}<0.05)$.

\section{DISCUSSION}

Obtaining highly accurate pharyngeal pressure measurements over prolonged periods in preterm infants receiving CPAP was difficult. Artefacts due to swallowing, movement, and secretions in the measuring catheters commonly rendered the recordings uninterpretable. However, satisfactory recordings were possible when the infants were quiet.

The results show that the prong pressure is not all transmitted to the pharynx, but is more effectively transmitted when the mouth is actively closed. There is considerable variation between infants in the pharyngeal pressure rise with mouth closure. This is predominantly due to variation in leak around the prongs at the nostrils. Air leak from between the lips also occurs despite jaw closure.

The mean pharyngeal pressure was never higher than the delivered pressure. This suggests that, with this CPAP system, there is always some pressure loss regardless of mouth position. We conclude that babies are unlikely to expire

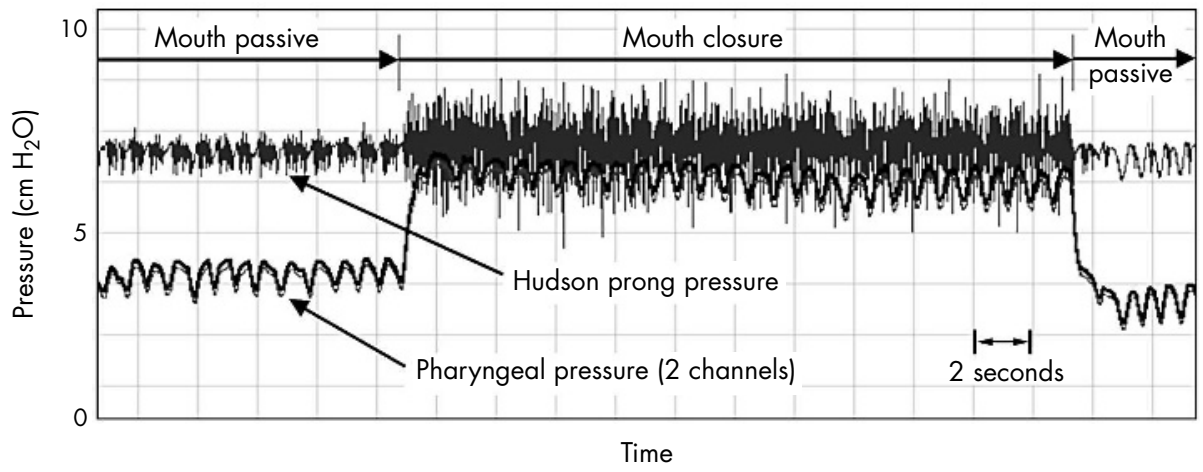

Figure 1 A 36 second recording of two pharyngeal pressures and the pressure in the Hudson prong nasal continuous positive airway pressure (CPAP) device from an infant with a birth weight of $1520 \mathrm{~g}$ receiving a nasal CPAP of $7 \mathrm{~cm} \mathrm{H} \mathrm{H}_{2} \mathrm{O}$ at a flow of 8 litres/min. During the first 10 seconds, the infant's mouth is open, then during the next 22 seconds it is closed, and in the last 4 seconds it is open. The pressure in the Hudson prong shows variation because it is pressurised by underwater bubbling. The amplitude increases with mouth closure, indicating less gas leak from the system and faster underwater bubbling. The two pharyngeal pressures are almost superimposed. The rhythmical pressure variation is due to infant breathing. 
through the CPAP device. If this is true with other devices, then nasal CPAP is unlikely to increase expiratory resistance. ${ }^{6}$

Some neonatal intensive care units use devices such as chinstraps and pacifiers to reduce mouth leak. However, many babies receiving nasal CPAP benefit even though their mouths are open. Clinicians should be aware that pressures transmitted to the airway may be very low when the mouth is not actively closed, particularly at low set pressures.

We speculate that pharyngeal pressures observed in preterm infants in this study (median age 14 days) are likely to be similar in those with respiratory distress syndrome in the first days of life. However, our results do not permit conclusions on the safety and effectiveness of active mouth closure during nasal CPAP.

\section{ACKNOWLEDGEMENTS}

Mr Ed Hingeley, Biomedical Engineer, Royal Women's Hospital, Melbourne, Australia. Professor John Dent, Professor of Gastroenterology, Royal Adelaide Hospital, Australia. Dr Taher Omari, Scientist, University of Adelaide, Australia. Nursing staff, babies, and parents of the neonatal intensive care unit of the Royal Women's Hospital, Melbourne, Australia.

\section{Authors' affiliations}

A G De Paoli, R Lau, P G Davis, C J Morley, Department of Paediatrics, Royal Women's Hospital, 132 Grattan Street, Carlton, Victoria 3053, Australia
P G Davis, C J Morley, Murdoch Children's Research Institute, Flemington Road, Parkville, Victoria 3052, Australia

AGDeP was supported by the Royal Women's Hospital Foundation and the Division of Research and Education, Royal Women's Hospital, Melbourne. PGD was supported by an NHMRC Practitioner Fellowship, Murdoch Children's Research Institute.

Competing interests: none declared

Correspondence to: Dr De Paoli, Special Care Baby Unit, Women's Centre, John Radcliffe Hospital, Headley Way, Headington, Oxford OX3 9DU, UK; depaolitony@netscape.net

Accepted 23 July 2004

\section{REFERENCES}

1 Morley CJ. Continuous distending pressure. Arch Dis Child Fetal Neonatal Ed 1999;81:F152-6.

2 De Paoli AG, Morley CJ, Davis PG, et al. In vitro comparison of nasal continuous positive airway pressure devices for neonates. Arch Dis Child Fetal Neonatal Ed 2002;87:F42-5.

3 Chilton HW, Brooks JG. Pharyngeal pressures in nasal CPAP. J Pediatr 1979;94:808-10.

4 Krouskop RW, Brown EG, Sweet AY. The early use of continuous positive airway pressure in the treatment of idiopathic respiratory distress syndrome. $J$ Pediatr 1975:87:263-7.

5 Omari TI, Benninga MA, Barnett CP, et al. Characterization of esophageal body and lower esophageal sphincter motor function in the very premature neonate. J Pediatr 1999;135:517-21.

6 Pandit PB, Courtney SE, Pyon KH, et al. Work of breathing during constantand variable-flow nasal continuous positive airway pressure in preterm neonates. Pediatrics 2001;108:682-5. 